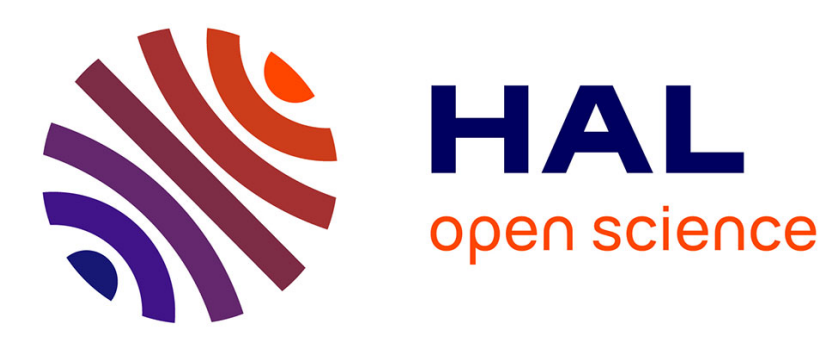

\title{
Synthesis and antiproliferative activities of isoindigo and azaisoindigo derivatives
}

Fadoua Bouchikhi, Fabrice Anizon, Pascale Moreau

\section{To cite this version:}

Fadoua Bouchikhi, Fabrice Anizon, Pascale Moreau. Synthesis and antiproliferative activities of isoindigo and azaisoindigo derivatives. European Journal of Medicinal Chemistry, 2008, 43, pp.755762. hal-00270595

\section{HAL Id: hal-00270595 https://hal.science/hal-00270595}

Submitted on 7 Apr 2008

HAL is a multi-disciplinary open access archive for the deposit and dissemination of scientific research documents, whether they are published or not. The documents may come from teaching and research institutions in France or abroad, or from public or private research centers.
L'archive ouverte pluridisciplinaire HAL, est destinée au dépôt et à la diffusion de documents scientifiques de niveau recherche, publiés ou non, émanant des établissements d'enseignement et de recherche français ou étrangers, des laboratoires publics ou privés. 


\title{
Synthesis and antiproliferative activities of isoindigo and azaisoindigo derivatives
}

\author{
Fadoua Bouchikhi, Fabrice Anizon, Pascale Moreau* \\ Laboratoire SEESIB, Université Blaise Pascal, UMR 6504 du CNRS, 24 avenue des Landais, F-63177 Aubière Cedex, France
}

\begin{abstract}
In the course of structure-activity relationship studies, diversely substituted 1-( $\beta$ - D-acetylatedglucopyranosyl)isoindigo derivatives were prepared from indolines. New $7^{\prime}$-azaisoindigo analogues were also synthesized by coupling a glycosylated isatine and a 7-azaindolin-2-one derivative. Compounds containing a $7^{\prime}$-azaisoindigo framework have never been described before. To get an insight into the substitution pattern required for the best biological potencies, their antiproliferative activities were evaluated toward a human buccal carcinoma cell line (KB) and two human myeloid leukaemia cell lines (K562, HL60).
\end{abstract}

Keywords: Indigoids; Isoindigos; $7^{\prime}$-Azaisoindigo; In vitro antiproliferative activities

\section{Introduction}

As part of our ongoing studies concerning the preparation of potential biologically active compounds, we were interested in the synthesis of diversely substituted isoindigo derivatives.

We have reported, in previous papers, the synthesis and antiproliferative activities of isoindigo derivatives bearing a sugar residue attached to one of the indole nitrogens and diversely substituted on the aromatic rings in the 5 or $5^{\prime}$ position (Scheme 1). The sugar moieties were either protected with benzyl or acetyl groups or unprotected. The results obtained in these previous structure-activity relationship studies have shown that the pharmaceutical profile of this series could be optimized by substitution of the upper oxindole moiety and the presence of acetyl groups on the sugar residue [1,2]. The acetylated-glycosyl derivatives we prepared in the past were only substituted on the lower oxindole part in the 5 position. Therefore, in this paper, the synthesis of acetylated-glycosylisoindigo derivatives diversely substituted in the 6 and/or $5^{\prime}$

\footnotetext{
* Corresponding author. Tel.: +334734079 63; fax: +334734077 17 . E-mail address: Pascale.MOREAU@univ-bpclermont.fr (P. Moreau).
}

and/or $6^{\prime}$ positions is described. Moreover, azaisoindigo analogues were also prepared to evaluate the influence of a 7 -azaindolin-2-one moiety instead of an indolin-2-one part on the biological activities of these compounds (Scheme 1). To our knowledge, this $7^{\prime}$-azaisoindigo framework, substituted or not, has never been described before. To get an insight into the effect of the substitution pattern on the biological activities of these compounds, their antiproliferative potencies were examined toward a human buccal carcinoma cell line (KB) and two human myeloid leukaemia cell lines (K562, HL60) using the classic colorimetric MTS test.

\section{Chemistry}

The key intermediates in this synthesis are the protected glycosyl-isatines 7 and $\mathbf{8}$ which were prepared in four steps from the corresponding glycosyl-indolines 1 and 2 , respectively. The preparation of compound 7 has been previously detailed [2]. Glycosyl-indolines 1 and 2 were prepared by glycosylation of the corresponding indolines. The hydroxy groups of the sugar moiety were first acetylated before aromatization with 2,3-dichloro-5,6-dicyanobenzoquinone (DDQ) 


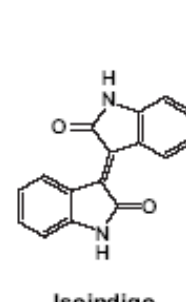

Isoindigo

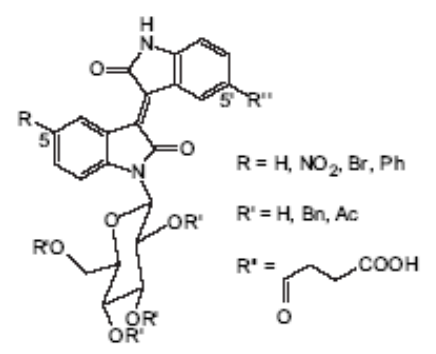

Diversely substituted glycosyl-isoindigos

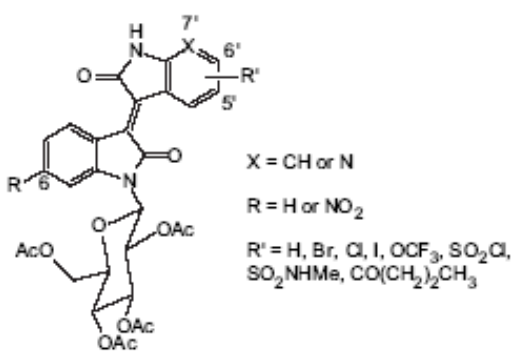

Acetylated glycosyl-isoindigos and 7 -azaisoindigos

Scheme 1 .

and oxidation with chromium oxide to give the glycosylisatines 7 and $\mathbf{8}$ (Scheme 2).

As mentioned in our previous paper for the synthesis of 1-(2,3,4,6-tetra- $O$-acetyl- $\beta$ - D-glucopyranosyl)-5-nitroindolin2,3-dione [2], the synthesis was more difficult in the presence of electron acceptor substituents. Indeed, the glycosylation step was achieved in $24 \mathrm{~h}$ for compound 1 and required 6 days for nitro analogue 2. The aromatization step was carried out at room temperature for $12 \mathrm{~h}$ for compound 5 and at $100^{\circ} \mathrm{C}$ for 3 days for nitro compound 6 . At last, the oxidation with chromium oxide was performed and it resulted in $88 \%$ yield for compound 7 and only $46 \%$ yield for the 6-nitro analogue 8 .

The required diversely substituted indolin-2-one derivatives were either commercially available (5 and 6-chlorooxindole) or prepared by standard methods (Scheme 3 ).

5-Iodoindolin-2-one 9 was prepared in $64 \%$ yield by treatment of 5-iodoindole with pyridinium bromide perbromide (PBPB) as previously described for indolin-2-one derivatives [3]. 7-Azaindolin-2-one $\mathbf{1 0}$ was prepared in 55\% overall yield by treatment with pyridinium bromide perbromide followed by debromination [4,5]. Bromo derivative 11 was prepared in $95 \%$ yield by bromination of the corresponding indolin-2-one using $\mathrm{N}$-bromosuccinimide [6]. 7-Aza-5bromoindolin-2-one $\mathbf{1 2}$ was prepared in two steps from the corresponding 7-azaindole as previously described [7]. Trifluoromethoxy derivative 13 was obtained in $45 \%$ yield by reduction of the corresponding isatine in the presence of hydrazine hydrate as described in the literature for the bromo derivative [8].

5-(1-Oxobutyl)indolin-2-one 14 was prepared in $48 \%$ yield by acylation of the indolin-2-one in the presence of butyryl chloride and aluminium chloride according to the procedure described by Kakushima et al. for pyrrole derivatives [9]. $5-\mathrm{N}$-Methylaminosulfonylindolin-2-one 16 was obtained in $63 \%$ yield by amidation of 5-chlorosulfonylindolin-2-one 15 that was prepared by sulfonylation of indolin-2-one with chlorosulfonic acid [10,11].

The final coupling step between isatines 7, 8 and indolin-2one or 7-azaindolin-2-one derivatives 9-16 was achieved in the presence of $p$-toluenesulfonic acid (PTSA) to give acetylated-glycosyl-isoindigo or $7^{\prime}$-azaisoindigo derivatives 17-27[11] (Scheme 2, Table 1). In the isoindigo series, the yields of the coupling step were usually lower when the reactions were performed with indolin-2-one substituted in the 5 position with an electron acceptor substituent (compounds 22-24), except when the isatine was activated with an electron acceptor substituent (compound 25). For the $7^{\prime}$-azaisoindigos, the reaction was also easier when the 7 -azaindolin-2-one was substituted with an electron donor substituent.

\section{Results and discussion}

In vitro antiproliferative activities of isoindigo (Scheme 1) and compounds 17-27 were evaluated in triplicate toward human buccal carcinoma cell line (KB) and human myeloid leukaemia cell lines (K562, HL60) using the classic colorimetric MTS test (Table 2). Taxotere was used as a positive control at a drug concentration of $2.5 \times 10^{-10} \mathrm{M}$. Percentage of cell proliferation inhibition was defined as absorbance in experimental wells compared with absorbance in control wells, after subtraction of the blank values. The $\mathrm{IC}_{50}$, defined as the drug concentration required to inhibit cell proliferation by $50 \%$, was calculated from the curve of concentration-dependent survival percentage. Under the conditions used $\left(10^{-5} \mathrm{M}\right.$ final concentration of tested compounds), isoindigo was active $\left(\mathrm{IC}_{50}=1.6 \mu \mathrm{M}\right)$ toward $\mathrm{KB}$ cells whereas it was slightly cytotoxic toward HL60 and K562 cell lines. None of the glycosylisoindigo derivatives $(\mathbf{1 7 - 2 5})$ exhibited relevant cytotoxicity toward the cell lines tested. Nevertheless, the two compounds bearing a $\mathbf{7}^{\prime}$-azaindolin-2-one moiety $(\mathbf{2 6}, \mathbf{2 7})$ have shown significant antiproliferative activities. Compound 26 inhibited the cell proliferation of all the cell lines tested in a $75-80 \%$ range $\left(\mathrm{KB} \mathrm{IC}_{50}=1.6 \mu \mathrm{M}\right)$. Compound 27 suppressed the cell proliferation of HL60 cells with a percentage of $73 \%$ whereas the cell proliferation of $\mathrm{KB}\left(\mathrm{IC}_{50}=13.9 \mu \mathrm{M}\right)$ and $\mathrm{K} 562$ cells was inhibited in a $60 \%$ range. Therefore, the presence of an extra nitrogen atom seems to be favourable for the cytotoxicity of these compounds.

In conclusion, we have synthesized diversely substituted 1 -(2,3,4,6-tetra- $O$-acetyl- $\beta$ - D-glucopyranosyl)isoindigos. The method described here allows the substitution of both aromatic rings by either electron donor or acceptor substituents in the 6 and/or $5^{\prime}, 6^{\prime}$ positions. Moreover, this synthetic approach allowed also the preparation of $7^{\prime}$-azaindolin-2-one analogues. The results obtained in this structure-activity relationship study have shown that the antiproliferative activities of this series 

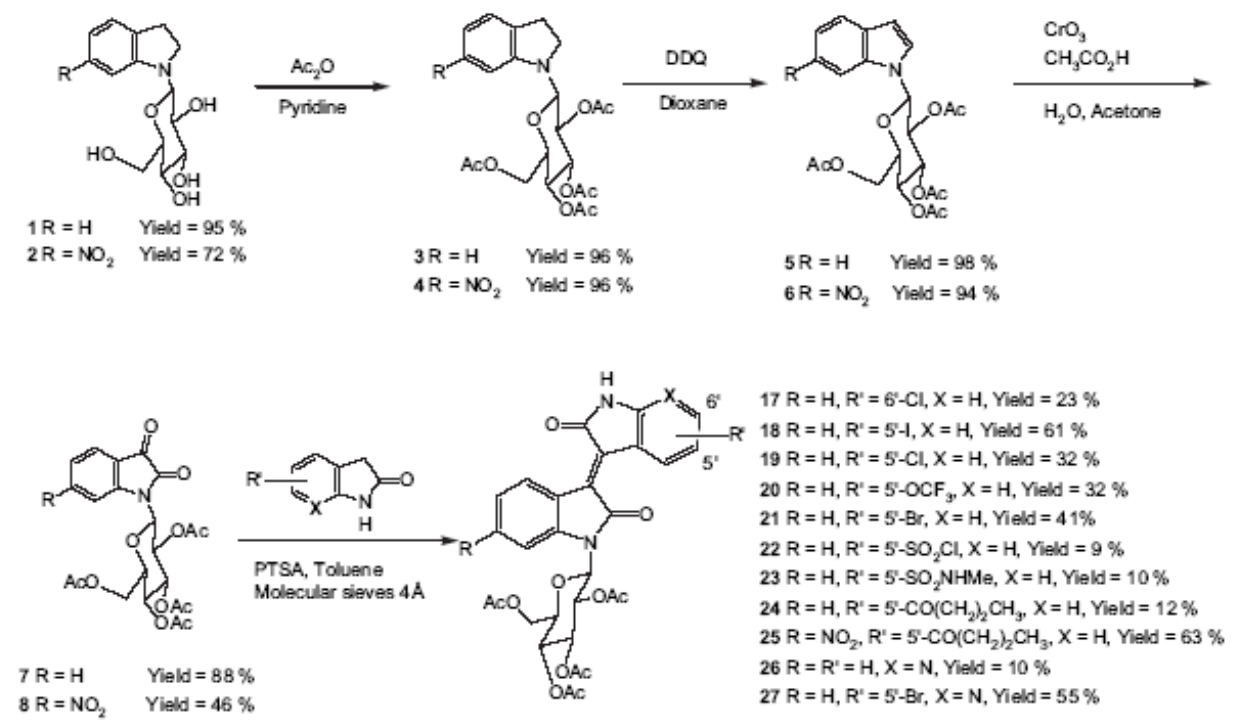

Scheme 2 .

could be optimized by the presence of a 7-azaindolin-2-one moiety. In this case, the replacement of a methine group by a nitrogen atom could reinforce the interaction with the biological target(s) involved in the cytotoxicity of these compounds. The preparation of diversely substituted $7^{\prime}$-azaindolin-2-one derivatives and the identification of the biological target(s) of these compounds are currently under investigation.

\section{Experimental}

\subsection{Chemistry}

IR spectra were recorded on a Perkin-Elmer Paragon 500 spectrometer $\left(\nu\right.$ in $\left.\mathrm{cm}^{-1}\right)$. NMR spectra were performed on a Bruker AVANCE $400\left({ }^{1} \mathrm{H}: 400 \mathrm{MHz},{ }^{13} \mathrm{C}: 100 \mathrm{MHz}\right)$ or

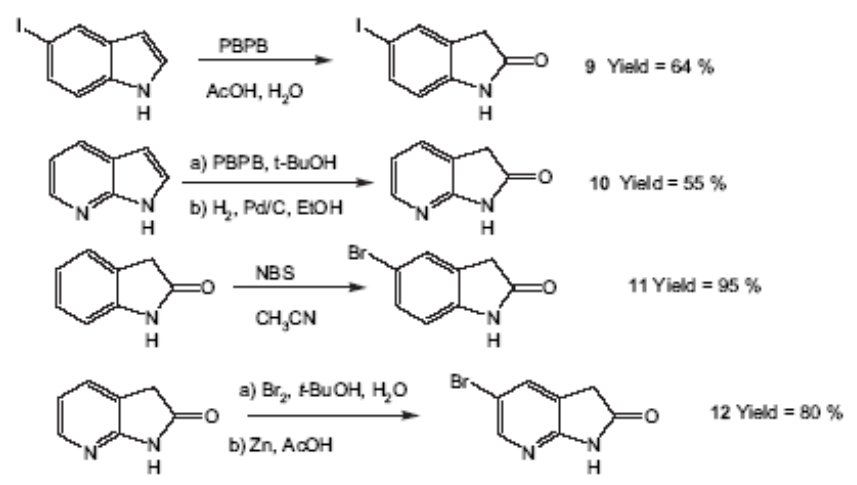<smiles>NNC1(C(F)(F)F)Oc2ccc3c(c2)CC(=O)N31</smiles>
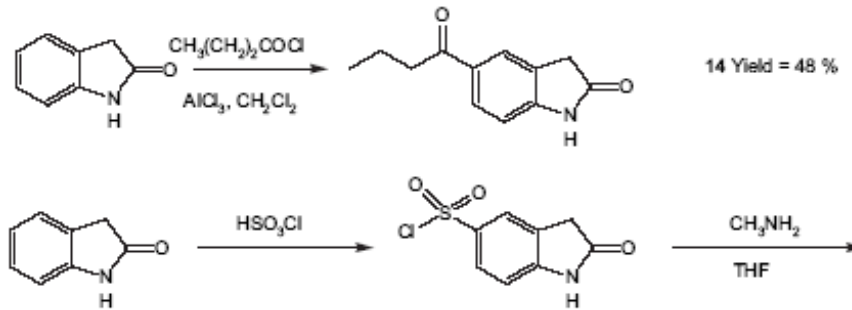<smiles>O=C1Cc2cc(S(=O)(=O)Cl)ccc2N1</smiles><smiles>NCCCN</smiles>

15 Yield $=93 \%$

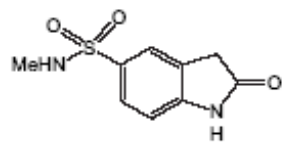

16 Yield $=63 \%$

Scheme 3. 
Table 1

\begin{tabular}{lllll}
\hline Compound & Isatine & $\begin{array}{l}\text { Indolin-2-one } \\
\text { (equiv) }\end{array}$ & $\begin{array}{l}\text { Reaction time } \\
\text { (h) }\end{array}$ & $\begin{array}{l}\text { Purification } \\
\text { method }\end{array}$ \\
\hline 17 & 7 & $6-C l-o x i n d o l e ~(2)$ & 48 & A \\
$18^{\mathrm{a}}$ & 7 & $9(1.2)$ & 30 & B \\
19 & 7 & $5-C l-o x i n d o l e ~(2)$ & 48 & A \\
20 & 7 & $13(1.1)$ & 36 & C \\
21 & 7 & $11(1.2)$ & 24 & C \\
22 & 7 & $15(1.1)$ & 48 & C \\
23 & 7 & $16(1.1)$ & 24 & C \\
24 & 7 & $14(2)$ & 48 & D \\
$25^{\text {b }}$ & 8 & $14(2)$ & 48 & A \\
$26^{\mathrm{b}}$ & 7 & $10(1.2)$ & 48 & C \\
27 & 7 & $12(1.2)$ & 48 & E \\
\hline
\end{tabular}

The reaction was performed in darkness.

b Isatine concentration was $15 \mathrm{mM}$ for compound 25 and $45 \mathrm{mM}$ for compound 26.

AVANCE $500\left({ }^{1} \mathrm{H}: 500 \mathrm{MHz},{ }^{13} \mathrm{C}: 125 \mathrm{MHz}\right)$, chemical shifts $\delta$ in ppm, the following abbreviations are used: singlet (s), doublet (d), triplet (t), quadruplet (q), doubled doublet (dd), sextuplet (sext), multiplet (m), broad signal (br s). When necessary to identify all carbon atoms, complementary NMR experiments (HSQC, HMBC) were performed on a Bruker AVANCE 500. Mass spectra (ES) were determined on a high resolution Waters Micro Q-toff apparatus. Chromatographic purifications were performed by flash silica gel Geduran SI 60 (Merck) $0.040-0.063 \mathrm{~mm}$ column chromatography. For purity tests, TLCs were performed on fluorescent silica gel plates ( $60 \mathrm{~F}_{254}$ from Merck).

\subsubsection{1-( $\beta$-D-Glucopyranosyl)-6-nitroindoline 2}

D-Glucose $(549 \mathrm{mg}, 3.1 \mathrm{mmol})$ was added to a solution of 6-nitroindoline $(1 \mathrm{~g}, 6.1 \mathrm{mmol})$ in a mixture of ethanol $(46.7 \mathrm{~mL})$ and water $(3.1 \mathrm{~mL})$. The mixture was refluxed for 6 days. Water $(0.6 \mathrm{~mL})$ was added after $7 \mathrm{~h}$ and $14 \mathrm{~h}$. After concentration under vacuum, the resulting mixture was purified by flash chromatography (eluent: $\mathrm{EtOAc} / \mathrm{MeOH}$ from 98:2 to $90: 10$ ) to give compound $\mathbf{2}$ in $72 \%$ yield as an orange

Table 2

\begin{tabular}{llll}
\hline Compound & KB & HL60 & K562 \\
\hline Taxotere $^{\mathrm{a}}$ & 71 & 46 & 32 \\
Isoindigo $^{17}$ & $92(1.6)$ & 53 & 64 \\
$\mathbf{1 8}$ & 42 & 22 & 30 \\
$\mathbf{1 9}$ & 49 & 45 & 49 \\
$\mathbf{2 0}$ & 38 & 47 & 56 \\
21 & 0 & 4 & 3 \\
22 & 34 & 49 & 58 \\
$\mathbf{2 3}$ & 35 & 0 & 1 \\
$\mathbf{2 4}$ & 19 & 0 & 13 \\
$\mathbf{2 5}$ & 13 & 29 & 33 \\
$\mathbf{2 6}$ & 41 & 58 & 50 \\
$\mathbf{2 7}$ & $76(1.6)$ & 70 & 75 \\
\hline
\end{tabular}

Percentage of cell proliferation inhibition at a drug concentration of $10^{-5} \mathrm{M}$; $\mathrm{IC}_{50}$ values $[\mu \mathrm{M}]$ are reported in brackets.

a Taxotere was used as a positive control at a drug concentration of $2.5 \times 10^{-10} \mathrm{M}$. solid $\left(\mathrm{mp}=195^{\circ} \mathrm{C}\right)$. IR $(\mathrm{KBr}): \nu_{\mathrm{C}=\mathrm{C}} 1610,1615 \mathrm{~cm}^{-1} ; \nu_{\mathrm{OH}}$ $3400 \mathrm{~cm}^{-1}$. HRMS (ES) calcd for $\mathrm{C}_{14} \mathrm{H}_{18} \mathrm{~N}_{2} \mathrm{NaO}_{7}(\mathrm{M}+\mathrm{Na})^{+}$ 349.1012, found 349.0995. ${ }^{1} \mathrm{H}$ NMR $\left(400 \mathrm{MHz}\right.$, DMSO- $\left.d_{6}\right)$ : $3.00-3.13(\mathrm{~m}, 3 \mathrm{H}), 2.28-3.36(\mathrm{~m}, 3 \mathrm{H}), 3.38-3.44(\mathrm{~m}, 1 \mathrm{H})$, $3.58-3.65(\mathrm{~m}, 2 \mathrm{H}), 3.72-3.80(\mathrm{~m}, 1 \mathrm{H}), 4.40(\mathrm{t}, J=6.5 \mathrm{~Hz}$, $1 \mathrm{H}, \mathrm{OH}), 4.80\left(\mathrm{~d}, J=9.0 \mathrm{~Hz}, 1 \mathrm{H}, \mathrm{H}_{1^{\prime}}\right), 4.95(\mathrm{~d}, J=5.0 \mathrm{~Hz}$, $1 \mathrm{H}, \mathrm{OH}), 5.07$ (d, $J=4.5 \mathrm{~Hz}, 1 \mathrm{H}, \mathrm{OH}), 5.10(\mathrm{~d}, J=5.0 \mathrm{~Hz}$, $1 \mathrm{H}, \mathrm{OH}), 7.24(\mathrm{~d}, J=8.5 \mathrm{~Hz}, 1 \mathrm{H}), 7.30(\mathrm{~d}, J=2.0 \mathrm{~Hz}, 1 \mathrm{H})$, $7.48 \quad\left(\mathrm{dd}, \quad J_{1}=8.5 \mathrm{~Hz}, \quad J_{2}=2.0 \mathrm{~Hz}, \quad 1 \mathrm{H}\right) .{ }^{13} \mathrm{C} \quad \mathrm{NMR}$ (100 MHz, DMSO- $\left.d_{6}\right): 27.4,45.7\left(\mathrm{CH}_{2}\right), 60.9\left(\mathrm{CH}_{2}\right.$ sugar $)$, $70.0,70.5,77.3,78.2,84.4\left(\mathrm{CH}_{\text {sugar }}\right), 100.6,113.3,124.5$ $(\mathrm{CH}), 138.3,147.9,152.0(\mathrm{C})$.

\subsubsection{6-Nitro-1-(2,3,4,6-tetra-O-acetyl- $\beta$ - \\ D-glucopyranosyl)indoline 4}

A solution of indoline 2 ( $960 \mathrm{mg}, 2.94 \mathrm{mmol}$ ) in pyridine $(10.3 \mathrm{~mL})$ was cooled to $0^{\circ} \mathrm{C}$ before addition of acetic anhydride $(7.5 \mathrm{~mL})$. The reaction mixture was stirred at room temperature for $24 \mathrm{~h}$. After addition of water and extraction with EtOAc, the organic phases were washed with water, saturated aqueous $\mathrm{NaHCO}_{3}$ and water until neutral $\mathrm{pH}$. After drying over $\mathrm{MgSO}_{4}$, the solvent was removed and the residue was purified by flash chromatography (eluent: cyclohexane/EtOAc $80: 20$ then 50:50) to give compound 4 in $96 \%$ yield as a yellow solid $\left(\mathrm{mp}=58^{\circ} \mathrm{C}\right)$. IR $(\mathrm{KBr}): \nu_{\mathrm{C}=\mathrm{O}} 1752 \mathrm{~cm}^{-1}$. HRMS (ES): calcd for $\mathrm{C}_{22} \mathrm{H}_{26} \mathrm{~N}_{2} \mathrm{NaO}_{11}(\mathrm{M}+\mathrm{Na})^{+}$517.1434, found 517.1453. ${ }^{1} \mathrm{H}$ NMR $\left(400 \mathrm{MHz}\right.$, DMSO- $\left.d_{6}\right): 1.92(\mathrm{~s}, 3 \mathrm{H}$, $\left.\mathrm{CH}_{3}\right), 1.94\left(\mathrm{~s}, 3 \mathrm{H}, \mathrm{CH}_{3}\right), 1.97\left(\mathrm{~s}, 3 \mathrm{H}, \mathrm{CH}_{3}\right), 2.01(\mathrm{~s}, 3 \mathrm{H}$, $\left.\mathrm{CH}_{3}\right), 2.90-3.02(\mathrm{~m}, 1 \mathrm{H}), 3.05-3.15(\mathrm{~m}, 1 \mathrm{H}), 3.56-3.64$ $(\mathrm{m}, 2 \mathrm{H}), 3.98-4.12(\mathrm{~m}, 2 \mathrm{H}), 4.15-4.21(\mathrm{~m}, 1 \mathrm{H}), 4.97(\mathrm{t}$, $J=10.0 \mathrm{~Hz}, 1 \mathrm{H}), \quad 5.18 \quad(\mathrm{t}, \quad J=9.5 \mathrm{~Hz}, 1 \mathrm{H}), \quad 5.45 \quad(\mathrm{t}$, $J=9.5 \mathrm{~Hz}, 1 \mathrm{H}), \quad 5.72 \quad(\mathrm{~d}, \quad J=9.5 \mathrm{~Hz}, 1 \mathrm{H}), 7.28 \quad(\mathrm{~d}$, $J=8.5 \mathrm{~Hz}, 1 \mathrm{H}), 7.55-7.58(\mathrm{~m}, 2 \mathrm{H}) .{ }^{13} \mathrm{C} \mathrm{NMR}(100 \mathrm{MHz}$, DMSO- $\left.d_{6}\right): 20.3-20.4(4 \mathrm{C})\left(\mathrm{CH}_{3}\right), 27.4,45.7,61.9\left(\mathrm{CH}_{2}\right)$, $68.2,68.4,72.0,72.8,81.6(\mathrm{CH}), 101.7,114.7,125.0(\mathrm{CH})$, $138.5,147.9,151.0(\mathrm{C}), 169.3,169.4,169.6,170.0(\mathrm{C}=\mathrm{O})$.

\subsection{6-Nitro-1-(2,3,4,6-tetra-O-acetyl- $\beta$ - D-glucopyranosyl)indole 6}

DDQ ( $210 \mathrm{mg}, 0.93 \mathrm{mmol}$ ) was added in portions to a solution of indoline 4 (350 mg, $0.71 \mathrm{mmol})$ in dioxane $(46 \mathrm{~mL})$. The mixture was stirred at $100^{\circ} \mathrm{C}$ for 3 days before addition of saturated aqueous $\mathrm{NaHCO}_{3}$. After extraction with EtOAc, the organic phases were washed with a brine solution, dried over $\mathrm{MgSO}_{4}$ and evaporated. The residue was purified by flash chromatography (eluent: cyclohexane/EtOAc 50:50) to give 6 in $94 \%$ yield as a yellow solid $\left(\mathrm{mp}=67^{\circ} \mathrm{C}\right)$. IR $(\mathrm{KBr}): \nu_{\mathrm{C}=0}$ $1753 \mathrm{~cm}^{-1}$. HRMS (ES) calcd for $\mathrm{C}_{22} \mathrm{H}_{24} \mathrm{~N}_{2} \mathrm{NaO}_{11}(\mathrm{M}+\mathrm{Na})^{+}$ 515.1278, found 515.1257. ${ }^{1} \mathrm{H}$ NMR (400 MHz, DMSO- $\left.d_{6}\right)$ : $1.62\left(\mathrm{~s}, 3 \mathrm{H}, \mathrm{CH}_{3}\right), 1.98\left(\mathrm{~s}, 3 \mathrm{H}, \mathrm{CH}_{3}\right), 2.00\left(\mathrm{~s}, 3 \mathrm{H}, \mathrm{CH}_{3}\right)$, $2.06\left(\mathrm{~s}, 3 \mathrm{H}, \mathrm{CH}_{3}\right), 4.09-4.18(\mathrm{~m}, 2 \mathrm{H}), 4.30-4.36(\mathrm{~m}, 1 \mathrm{H})$, $5.28(\mathrm{t}, J=9.5 \mathrm{~Hz}, 1 \mathrm{H}), 5.56(\mathrm{t}, J=9.5 \mathrm{~Hz}, 1 \mathrm{H}), 5.64(\mathrm{t}$, $J=9.0 \mathrm{~Hz}, 1 \mathrm{H}), \quad 6.48 \quad(\mathrm{~d}, \quad J=9.0 \mathrm{~Hz}, 1 \mathrm{H}), 6.76 \quad(\mathrm{~d}$, $J=3.5 \mathrm{~Hz}, 1 \mathrm{H}), \quad 7.77 \quad(\mathrm{~d}, J=9.0 \mathrm{~Hz}, 1 \mathrm{H}), 7.96 \quad(\mathrm{~d}$, $J=3.5 \mathrm{~Hz}, 1 \mathrm{H}), 7.98\left(\mathrm{dd}, J_{1}=9.0 \mathrm{~Hz}, J_{2}=2.0 \mathrm{~Hz}, 1 \mathrm{H}\right)$, $8.71(\mathrm{~d}, J=2.0 \mathrm{~Hz}, 1 \mathrm{H}) .{ }^{13} \mathrm{C}$ NMR $\left(100 \mathrm{MHz}, \mathrm{DMSO}-d_{6}\right)$ : 19.7, 20.2, 20.4, $20.5\left(\mathrm{CH}_{3}\right), 61.9\left(\mathrm{CH}_{2}\right), 67.8,70.2,72.3$, 
$73.2,81.2(\mathrm{CH}), 104.3,107.0,115.4,121.2,132.2(\mathrm{CH})$, $133.3,134.7,142.8(\mathrm{C}), 168.4,169.4,169.6,170.0(\mathrm{C}=\mathrm{O})$.

\subsubsection{6-Nitro-1- $(2,3,4,6$-tetra-O-acetyl- $\beta$ - D-glucopyranosyl)indoline-2,3-dione 8}

Chromium oxide ( $285 \mathrm{mg}, 2.85 \mathrm{mmol})$ was added in portions to a suspension of indole derivative $6(150 \mathrm{mg}$, $0.305 \mathrm{mmol})$ in a mixture of acetone $(0.5 \mathrm{~mL})$, acetic acid $(2.3 \mathrm{~mL})$ and water $(0.8 \mathrm{~mL})$. The reaction mixture was stirred at room temperature for $5 \mathrm{~h}$ before addition of cold water. The solid was isolated by filtration to give the corresponding isatine 8 in $46 \%$ yield as a yellow solid $\left(\mathrm{mp}=110^{\circ} \mathrm{C}\right)$. IR $(\mathrm{KBr}): \nu_{\mathrm{C}=\mathrm{O}} 1715-1800 \mathrm{~cm}^{-1}$. HRMS (ES) calcd for $\mathrm{C}_{22} \mathrm{H}_{22} \mathrm{~N}_{2} \mathrm{NaO}_{13}(\mathrm{M}+\mathrm{Na})^{+} 545.1020$, found 545.1003 . ${ }^{1} \mathrm{H}$ NMR $\left(400 \mathrm{MHz}, \mathrm{CDCl}_{3}\right): 1.94\left(\mathrm{~s}, 3 \mathrm{H}, \mathrm{CH}_{3}\right), 2.06(\mathrm{~s}, 3 \mathrm{H}$, $\left.\mathrm{CH}_{3}\right), 2.10\left(\mathrm{~s}, 3 \mathrm{H}, \mathrm{CH}_{3}\right), 2.21\left(\mathrm{~s}, 3 \mathrm{H}, \mathrm{CH}_{3}\right), 3.97-4.01(\mathrm{~m}$, $1 \mathrm{H}), 4.21\left(\mathrm{dd}, J_{1}=12.5 \mathrm{~Hz}, J_{2}=2.0 \mathrm{~Hz}, 1 \mathrm{H}\right), 4.38(\mathrm{dd}$, $\left.J_{1}=13.0 \mathrm{~Hz}, J_{2}=3.0 \mathrm{~Hz}, 1 \mathrm{H}\right), 5.37(\mathrm{t}, J=9.5 \mathrm{~Hz}, 1 \mathrm{H}), 5.44$ $(\mathrm{t}, \quad J=9.5 \mathrm{~Hz}, 1 \mathrm{H}), 5.48(\mathrm{t}, J=9.5 \mathrm{~Hz}, 1 \mathrm{H}), 5.74(\mathrm{~d}$, $J=9.0 \mathrm{~Hz}, 1 \mathrm{H}), 7.85(\mathrm{~d}, J=8.0 \mathrm{~Hz}, 1 \mathrm{H}), 8.10 \quad(\mathrm{dd}$, $\left.J_{1}=8.0 \mathrm{~Hz}, J_{2}=2.0 \mathrm{~Hz}, 1 \mathrm{H}\right), 8.17(\mathrm{~d}, J=1.5 \mathrm{~Hz}, 1 \mathrm{H}) .{ }^{13} \mathrm{C}$ NMR $\left(100 \mathrm{MHz}, \mathrm{CDCl}_{3}\right): 20.3,20.6$ (3C) $\left(\mathrm{CH}_{3}\right), 60.8$ $\left(\mathrm{CH}_{2}\right), 67.2,68.1,72.4,75.0,80.4(\mathrm{CH}), 109.2,119.9,126.5$ $(\mathrm{CH}), 121.2,148.6,153.5$ (C), 156.3, 169.4, 169.8, 169.9, $170.8,180.6(\mathrm{C}=\mathrm{O})$.

\subsubsection{5-Iodoindolin-2-one 9}

To a solution of 5 -iodoindole $(500 \mathrm{mg}, 2.06 \mathrm{mmol})$ in a mixture of acetic acid and water $(100: 10 \mathrm{~mL})$ was added a solution of pyridinium bromide perbromide $(790 \mathrm{mg}$, $2.47 \mathrm{mmol})$ in acetic acid $(100 \mathrm{~mL})$. The reaction mixture was heated at $80^{\circ} \mathrm{C}$ for $24 \mathrm{~h}$ before evaporation and addition of $10 \%$ aqueous $\mathrm{Na}_{2} \mathrm{CO}_{3}$. After extraction with EtOAc, the combined organic phases were dried over $\mathrm{MgSO}_{4}$, evaporated and the residue was purified by flash chromatography (eluent: cyclohexane/EtOAc 80:20) to give compound 9 in 64\% yield as a grey solid $\left(\mathrm{mp}=170-172{ }^{\circ} \mathrm{C}\right)$. IR $(\mathrm{KBr}): \nu_{\mathrm{C}=\mathrm{C}}$ $1609 \mathrm{~cm}^{-1} ; \nu_{\mathrm{C}=\mathrm{O}} 1704 \mathrm{~cm}^{-1} ; \nu_{\mathrm{NH}} 3150 \mathrm{~cm}^{-1}$. HRMS (ES) calcd for $\mathrm{C}_{8} \mathrm{H}_{7} \mathrm{INO}(\mathrm{M}+\mathrm{H})^{+} 259.9572$, found $259.9577 .{ }^{1} \mathrm{H}$ NMR $\left(400 \mathrm{MHz}, \quad\right.$ DMSO- $\left.d_{6}\right): 3.48(\mathrm{~s}, 2 \mathrm{H}), 6.65$ (d, $J=8.0 \mathrm{~Hz}, 1 \mathrm{H}), 7.48-7.52(\mathrm{~m}, 2 \mathrm{H}), 10.47(\mathrm{~s}, 1 \mathrm{H}, \mathrm{NH}) .{ }^{13} \mathrm{C}$ NMR (100 MHz, DMSO- $\left.d_{6}\right): 35.5\left(\mathrm{CH}_{2}\right), 111.5,132.7$, $135.9(\mathrm{CH}), 83.9,128.8,143.5(\mathrm{C}), 175.8(\mathrm{C}=\mathrm{O})$.

\subsubsection{5-Trifluoromethoxyindolin-2-one 13}

Potassium hydroxide (147 mg) and hydrazine hydrate $(678 \mu \mathrm{L}, 12.0 \mathrm{mmol})$ were added to a solution of 5-trifluoromethoxyisatine $(100 \mathrm{mg}, 0.43 \mathrm{mmol})$ in ethylene glycol $(0.6 \mathrm{~mL})$. The mixture was stirred at $70^{\circ} \mathrm{C}$ for $30 \mathrm{~min}$. After addition of water, the mixture was neutralized with $10 \%$ aqueous $\mathrm{HCl}$ and extracted with EtOAc. The combined organic phases were dried over $\mathrm{MgSO}_{4}$, evaporated and the residue was purified by flash chromatography (eluent: cyclohexane/ EtOAc 70:30) to give compound $\mathbf{1 3}$ in $45 \%$ yield as a pink solid $\left(\mathrm{mp}=140^{\circ} \mathrm{C}\right)$. IR $(\mathrm{KBr}): \nu_{\mathrm{C}=\mathrm{C}} 1669 \mathrm{~cm}^{-1} ; \nu_{\mathrm{C}=\mathrm{O}}$ $1705 \mathrm{~cm}^{-1} ; \nu_{\mathrm{NH}} 3298 \mathrm{~cm}^{-1}$. HRMS (ES) calcd for $\mathrm{C}_{9} \mathrm{H}_{7}$ $\mathrm{F}_{3} \mathrm{NO}_{2}(\mathrm{M}+\mathrm{H})^{+}$218.0429, found 218.0431. ${ }^{1} \mathrm{H}$ NMR $\left(400 \mathrm{MHz}\right.$, DMSO- $\left.d_{6}\right): 3.54(\mathrm{~s}, 2 \mathrm{H}), 6.86(\mathrm{~d}, J=8.5 \mathrm{~Hz}$, $1 \mathrm{H}), 7.16(\mathrm{~d}, J=8.5 \mathrm{~Hz}, 1 \mathrm{H}), 7.24(\mathrm{~s}, 1 \mathrm{H}), 10.47$ (br s, $1 \mathrm{H}$, $\mathrm{NH}) .{ }^{13} \mathrm{C}\left(100 \mathrm{MHz}, \mathrm{DMSO}-d_{6}\right): 36.0\left(\mathrm{CH}_{2}\right), 109.6,118.2$, $120.6(\mathrm{CH}), 120.2\left(\mathrm{q}, J_{\mathrm{C}, \mathrm{F}}=255 \mathrm{~Hz}, \mathrm{OCF}_{3}\right), 127.7,142.8$, 142.9 (C), $176.3(\mathrm{C}=\mathrm{O})$.

\subsubsection{5-(1-Oxobutyl)indolin-2-one 14}

Butanoyl chloride $(1.19 \mathrm{~mL}, 11.5 \mathrm{mmol})$ was added to a suspension of aluminium chloride $(3.0 \mathrm{~g}, 22.5 \mathrm{mmol})$ in $\mathrm{CH}_{2} \mathrm{Cl}_{2}(15.5 \mathrm{~mL})$. The mixture was stirred at room temperature for $15 \mathrm{~min}$ before addition of a solution of oxindole (500 mg, $3.76 \mathrm{mmol})$ in $\mathrm{CH}_{2} \mathrm{Cl}_{2}(10 \mathrm{~mL})$. The mixture was stirred at room temperature for $48 \mathrm{~h}$ before hydrolysis and extraction with EtOAc. The combined organic phases were washed with saturated aqueous $\mathrm{NaHCO}_{3}$, dried over $\mathrm{MgSO}_{4}$, evaporated and the residue was purified by flash chromatography (eluent: cyclohexane/EtOAc from 90:10 to 60:40) to give compound 14 in $48 \%$ yield as a white solid $(\mathrm{mp}=143-$ $\left.144^{\circ} \mathrm{C}\right)$. IR $(\mathrm{KBr}): \nu_{\mathrm{C}-\mathrm{C}} \quad 1610 \mathrm{~cm}^{-1} ; \quad \nu_{\mathrm{C}-\mathrm{O}} \quad 1675$, $1717 \mathrm{~cm}^{-1} ; \nu_{\mathrm{NH}} 3000-3280 \mathrm{~cm}^{-1}$. HRMS (ES) calcd for $\mathrm{C}_{12} \mathrm{H}_{14} \mathrm{NO}_{2}(\mathrm{M}+\mathrm{H})^{+}$204.1025, found 204.1029. ${ }^{1} \mathrm{H}$ NMR (400 MHz, DMSO- $d_{6}$ ): 0.91 (t, $\left.J=7.5 \mathrm{~Hz}, 3 \mathrm{H}, \mathrm{CH}_{3}\right), 1.61$ (sext, $J=7.5 \mathrm{~Hz}, 2 \mathrm{H}, \mathrm{CH}_{2}$ ), $2.91\left(\mathrm{t}, J=7.0 \mathrm{~Hz}, 2 \mathrm{H}, \mathrm{CH}_{2}\right.$ ), $3.55(\mathrm{~s}, 2 \mathrm{H}), 6.89(\mathrm{~d}, J=8.0 \mathrm{~Hz}, 1 \mathrm{H}), 7.81(\mathrm{~s}, 1 \mathrm{H}), 7.86$ (dd, $\left.J_{1}=8.0 \mathrm{~Hz}, J_{2}=1.5 \mathrm{~Hz}, 1 \mathrm{H}\right), 10.75(\mathrm{br} \mathrm{s}, 1 \mathrm{H}, \mathrm{NH}) .{ }^{13} \mathrm{C}$ NMR (100 MHz, DMSO- $\left.d_{6}\right): 13.7\left(\mathrm{CH}_{3}\right), 17.6,35.5,39.4$ $\left(\mathrm{CH}_{2}\right), 108.7,124.1,129.0(\mathrm{CH}), 126.1,130.4,148.2(\mathrm{C})$, $176.8,198.5(\mathrm{C}=\mathrm{O})$.

\subsubsection{5-Chlorosulfonylindolin-2-one 15}

Oxindole $(5.0 \mathrm{~g}, 37.6 \mathrm{mmol})$ was added in portions in chlorosulfonic acid $(10.2 \mathrm{~mL})$ at $30^{\circ} \mathrm{C}$. The mixture was stirred at room temperature for $1.5 \mathrm{~h}$ and heated at $70^{\circ} \mathrm{C}$ for $1 \mathrm{~h}$. After addition of water, the solid was collected by filtration and washed with water to give compound 15 in $93 \%$ yield as a pink solid $\left(\mathrm{mp}=185^{\circ} \mathrm{C}\right) . \mathrm{IR}(\mathrm{KBr}): \nu_{\mathrm{C}-\mathrm{C}} 1610 \mathrm{~cm}^{-1}$; $\nu_{\mathrm{C}=\mathrm{O}} 1715 \mathrm{~cm}^{-1} ; \nu_{\mathrm{NH}} 3110 \mathrm{~cm}^{-1}$. HRMS (ES) calcd for $\mathrm{C}_{8} \mathrm{H}_{6} \mathrm{NO}_{3} \mathrm{~S}(\mathrm{M}-\mathrm{Cl})^{+} 196.0068$, found 196.0078. ${ }^{1} \mathrm{H}$ NMR $\left(400 \mathrm{MHz}\right.$, DMSO- $\left.d_{6}\right): 3.46(\mathrm{~s}, 2 \mathrm{H}), 6.72(\mathrm{~d}, J=8.0 \mathrm{~Hz}$, 1H), 7.40-7.45 (m, 2H), 10.43 (br s, $1 \mathrm{H}, \mathrm{NH}) .{ }^{13} \mathrm{C}$ NMR $\left(100 \mathrm{MHz}\right.$, DMSO- $\left.d_{6}\right): 36.1\left(\mathrm{CH}_{2}\right), 108.5,122.3,125.6$ $(\mathrm{CH}), 125.7,140.3,144.9(\mathrm{C}), 177.0(\mathrm{C}=\mathrm{O})$.

\subsubsection{5-N-Methylaminosulfonylindolin-2-one 16}

Methylamine $2 \mathrm{M} / \mathrm{THF}(1.16 \mathrm{~mL}, 2.32 \mathrm{mmol})$ was added dropwise to a solution of 5-chlorosulfonylindolin-2-one $\mathbf{1 5}$ (200 mg, $0.86 \mathrm{mmol}$ ) in THF cooled to $0^{\circ} \mathrm{C}$. The mixture was stirred at room temperature for $24 \mathrm{~h}$ before evaporation and purification of the residue by flash chromatography (eluent: cyclohexane/EtOAc 50:50 then 30:70) to give compound 16 in $63 \%$ yield as a pink solid $\left(\mathrm{mp}=190^{\circ} \mathrm{C}\right)$. IR $(\mathrm{KBr})$ : $\nu_{\mathrm{C}-\mathrm{C}} 1620 \mathrm{~cm}^{-1} ; \nu_{\mathrm{C}-\mathrm{O}} 1696 \mathrm{~cm}^{-1} ; \nu_{\mathrm{NH}} 3050-3410 \mathrm{~cm}^{-1}$. HRMS (ES) calcd for $\mathrm{C}_{9} \mathrm{H}_{10} \mathrm{~N}_{2} \mathrm{NaO}_{3} \mathrm{~S}(\mathrm{M}+\mathrm{Na})^{+} 249.0310$, found $249.0314 .{ }^{1} \mathrm{H}$ NMR $\left(400 \mathrm{MHz}\right.$, DMSO- $d_{6}$ ): 2.38 (d, $J=4.5 \mathrm{~Hz}, 3 \mathrm{H}), 3.59(\mathrm{~s}, 2 \mathrm{H}), 6.97(\mathrm{~d}, J=8.0 \mathrm{~Hz}, 1 \mathrm{H})$, $7.22-7.27\left(\mathrm{~m}, 1 \mathrm{H}, \mathrm{NHCH} \mathrm{CH}_{3}, 7.58(\mathrm{~s}, 1 \mathrm{H}), 7.61\right.$ (dd, $\left.J_{1}=8.0 \mathrm{~Hz}, \quad J_{2}=2.0 \mathrm{~Hz}, 1 \mathrm{H}\right), 10.76(\mathrm{br} \mathrm{s}, 1 \mathrm{H}, \quad \mathrm{NH})$. 
${ }^{13} \mathrm{C}$ NMR $\left(100 \mathrm{MHz}, \mathrm{DMSO}-d_{6}\right): 28.7\left(\mathrm{CH}_{3}\right), 35.6\left(\mathrm{CH}_{2}\right)$, $108.9,122.9,127.4(\mathrm{CH}), 126.7,131.6,147.4(\mathrm{C}), 176.5(\mathrm{C}=\mathrm{O})$.

\subsubsection{Typical procedure for the acid-catalysed coupling reaction}

To an anhydrous solution of PTSA ( 0.3 equiv) in toluene were added acetylated-glycosyl-isatine $(21 \mathrm{mM})$, indolin-2one derivative and $4 \AA$ molecular sieves. The mixture was refluxed from 24 to $48 \mathrm{~h}$. After cooling, EtOAc was added, the organic phase was washed with water. After drying over $\mathrm{MgSO}_{4}$, the solvent was removed and the residue purified in different conditions depending on the compounds (Table 1):

\begin{abstract}
- Method A: flash chromatography (eluent: cyclohexane/ EtOAc 40:60 then cyclohexane/EtOAc 40:60 (0.01\% $\mathrm{AcOH})$ ) to give crude solid which was refluxed in cyclohexane before filtration to give the attempted compound.

- Method B: flash chromatography (eluent: cyclohexane/ EtOAc 50:50 then cyclohexane/EtOAc 50:50 (0.01\% $\mathrm{AcOH})$ ) to give a residue which was precipitated in a mixture of $\mathrm{AcOH} /$ toluene 50:50 with a few drops of water. After filtration, the solid was refluxed in cyclohexane before filtration to give the attempted compound.

- Method C: flash chromatography (eluent: cyclohexane/ EtOAc 50:50 then cyclohexane/EtOAc 50:50 (0.01\% $\mathrm{AcOH})$ ) to give a residue which was precipitated in a mixture of AcOH/toluene 50:50 with a few drops of water before filtration to give the attempted compound.

- Method D: flash chromatography (eluent: cyclohexane/ EtOAc 40:60 then cyclohexane/EtOAc 40:60 (0.01\% $\mathrm{AcOH})$ ) to give the attempted compound without further purification.

- Method E: flash chromatography (eluent: cyclohexane/ EtOAc 50:50 then cyclohexane/EtOAc 50:50 (0.01\% $\mathrm{AcOH})$ ) to give directly the attempted compound.
\end{abstract}

4.1.10.1. 6'-Chloro-1-(2,3,4,6-tetra-O-acetyl- $\beta$-D-glucopyranosyl)isoindigo 17. Yield: $23 \%$. Red solid $\left(\mathrm{mp}>280^{\circ} \mathrm{C}\right)$. IR $(\mathrm{KBr}): \quad \nu_{\mathrm{C}-\mathrm{C}} \quad 1615 \mathrm{~cm}^{-1} ; \quad \nu_{\mathrm{C}=\mathrm{O}} \quad 1700-1800 \mathrm{~cm}^{-1} ; \quad \nu_{\mathrm{NH}}$ $3215-3615 \mathrm{~cm}^{-1}$. HRMS (ES) calcd for $\mathrm{C}_{30} \mathrm{H}_{27}{ }^{35} \mathrm{ClN}_{2} \mathrm{NaO}_{11}$ $(\mathrm{M}+\mathrm{Na})^{+}$649.1201, found 649.1196. ${ }^{1} \mathrm{H} \mathrm{NMR}(400 \mathrm{MHz}$, DMSO-d $\left.d_{6}\right): 1.77\left(\mathrm{~s}, 3 \mathrm{H}, \mathrm{CH}_{3}\right), 1.96\left(\mathrm{~s}, 3 \mathrm{H}, \mathrm{CH}_{3}\right), 2.02$ (s, 3H, $\left.\mathrm{CH}_{3}\right), 2.05\left(\mathrm{~s}, 3 \mathrm{H}, \mathrm{CH}_{3}\right), 4.09-4.21$ (br s, 2H), $4.31-4.40(\mathrm{~m}, 1 \mathrm{H}), 5.24-5.39(\mathrm{~m}, 1 \mathrm{H}), 5.52-5.71(\mathrm{~m}, 2 \mathrm{H})$, $6.03-6.13(\mathrm{~m}, 1 \mathrm{H}), 6.88(\mathrm{~s}, 1 \mathrm{H}), 7.05(\mathrm{~d}, J=8.0 \mathrm{~Hz}, 1 \mathrm{H})$, $7.10(\mathrm{t}, \quad J=7.5 \mathrm{~Hz}, 1 \mathrm{H}), 7.42-7.57(\mathrm{~m}, 2 \mathrm{H}), 8.92(\mathrm{~d}$, $J=8.5 \mathrm{~Hz}, 1 \mathrm{H}), 9.09(\mathrm{~d}, J=8.0 \mathrm{~Hz}, 1 \mathrm{H}), 11.12(\mathrm{~s}, 1 \mathrm{H}$, $\mathrm{NH}) .{ }^{13} \mathrm{C}$ NMR $\left(125 \mathrm{MHz}\right.$, DMSO- $\left.d_{6}\right): 20.0,20.3,20.4$, $20.5\left(\mathrm{CH}_{3}\right), 61.9\left(\mathrm{CH}_{2}\right), 67.3,67.8,72.5,73.1,78.3(\mathrm{CH})$, $109.7,112.2,121.0,122.4,128.9,130.6,132.9(\mathrm{CH}), 120.3$, $120.8,131.3,133.3,137.0,141.2,145.7$ (C), 166.9, 168.6, $168.8,169.4,169.5,170.0(\mathrm{C}=\mathrm{O})$.

4.1.10.2. $\quad 5^{\prime}$-Iodo-1-(2,3,4,6-tetra-O-acetyl- $\beta$-D-glucopyranosyl $)$ isoindigo 18. Yield: $61 \%$. Red solid $\left(\mathrm{mp}=228-230^{\circ} \mathrm{C}\right)$. IR $(\mathrm{KBr}): \quad \nu_{\mathrm{C}-\mathrm{C}} \quad 1610 \mathrm{~cm}^{-1} ; \quad \nu_{\mathrm{C}=\mathrm{O}} \quad 1675-1785 \mathrm{~cm}^{-1} ; \quad \nu_{\mathrm{NH}}$
$3285-3615 \mathrm{~cm}^{-1}$. HRMS (ES) calcd for $\mathrm{C}_{30} \mathrm{H}_{27} \mathrm{IN}_{2} \mathrm{NaO}_{11}$ $(\mathrm{M}+\mathrm{Na})^{+} 741.0557$, found 741.0574. ${ }^{1} \mathrm{H} \mathrm{NMR}(400 \mathrm{MHz}$, DMSO-d $\left.d_{6}\right): 1.78\left(\mathrm{~s}, 3 \mathrm{H}, \mathrm{CH}_{3}\right), 1.96\left(\mathrm{~s}, 3 \mathrm{H}, \mathrm{CH}_{3}\right), 2.03(\mathrm{~s}$, $\left.3 \mathrm{H}, \mathrm{CH}_{3}\right), 2.05\left(\mathrm{~s}, 3 \mathrm{H}, \mathrm{CH}_{3}\right), 4.11-4.18(\mathrm{~m}, 2 \mathrm{H}), 4.32-4.38$ $(\mathrm{m}, 1 \mathrm{H}), 5.28-5.38(\mathrm{~m}, 1 \mathrm{H}), 5.52-5.68(\mathrm{~m}, 1 \mathrm{H}), 5.58(\mathrm{t}$, $J=9.0 \mathrm{~Hz}, 1 \mathrm{H}), 6.13-6.21(\mathrm{~m}, 1 \mathrm{H}), 6.71(\mathrm{~d}, J=8.0 \mathrm{~Hz}$, $1 \mathrm{H}), 7.10(\mathrm{t}, J=8.0 \mathrm{~Hz}, 1 \mathrm{H}), 7.46(\mathrm{t}, J=8.0 \mathrm{~Hz}, 1 \mathrm{H})$, $7.49-7.56(\mathrm{~m}, 1 \mathrm{H}), 7.69\left(\mathrm{dd}, J_{1}=8.0 \mathrm{~Hz}, J_{2}=1.5 \mathrm{~Hz}, 1 \mathrm{H}\right)$, $9.11(\mathrm{~d}, J=8.0 \mathrm{~Hz}, 1 \mathrm{H}), 9.33(\mathrm{~s}, 1 \mathrm{H}), 11.09(\mathrm{~s}, 1 \mathrm{H}, \mathrm{NH})$. ${ }^{13} \mathrm{C}$ NMR (125 MHz, DMSO-d $\left.d_{6}\right): 19.9,20.3,20.4,20.5$ $\left(\mathrm{CH}_{3}\right), 61.9\left(\mathrm{CH}_{2}\right), 67.3,67.8,72.5,73.1,78.3(\mathrm{CH}), 112.1$ (2C), 122.5, 129.0, 133.1, 137.0, $140.9(\mathrm{CH}), 84.0,120.7$, $123.7,132.0,133.2,141.2,143.9$ (C), 167.0, 168.0, 168.8, $169.4,169.5,170.0(\mathrm{C}=\mathrm{O})$.

4.1 10.3. 5'-Chloro-1-(2,3,4,6-tetra-O-acetyl- $\beta$-D-glucopyranosyl)isoindigo 19. Yield: $32 \%$. Red solid $\left(\mathrm{mp}=242^{\circ} \mathrm{C}\right)$. IR $(\mathrm{KBr}): \quad \nu_{\mathrm{C}=\mathrm{C}} 1611 \mathrm{~cm}^{-1} ; \quad \nu_{\mathrm{C}=\mathrm{O}} 1695-1795 \mathrm{~cm}^{-1} ; \nu_{\mathrm{NH}}$ $3120-3570 \mathrm{~cm}^{-1}$. HRMS (ES) calcd for $\mathrm{C}_{30} \mathrm{H}_{27}{ }^{35} \mathrm{ClN}_{2} \mathrm{NaO}_{11}$ $(\mathrm{M}+\mathrm{Na})^{+}$649.1201, found 649.1213. ${ }^{1} \mathrm{H}$ NMR $(400 \mathrm{MHz}$, DMSO- $\left.d_{6}\right): 1.78\left(\mathrm{~s}, 3 \mathrm{H}, \mathrm{CH}_{3}\right), 1.96\left(\mathrm{~s}, 3 \mathrm{H}, \mathrm{CH}_{3}\right), 2.03(\mathrm{~s}$, $\left.3 \mathrm{H}, \mathrm{CH}_{3}\right), 2.05\left(\mathrm{~s}, 3 \mathrm{H}, \mathrm{CH}_{3}\right), 4.11-4.18(\mathrm{~m}, 2 \mathrm{H}), 4.32-4.38$ $(\mathrm{m}, 1 \mathrm{H}), 5.29-5.37(\mathrm{~m}, 1 \mathrm{H}), 5.58(\mathrm{t}, J=9.5 \mathrm{~Hz}, 1 \mathrm{H}), 5.54-$ $5.70(\mathrm{~m}, 1 \mathrm{H}), 6.10-6.18(\mathrm{~m}, 1 \mathrm{H}), 6.87(\mathrm{~d}, J=8.5 \mathrm{~Hz}, 1 \mathrm{H})$, $7.11(\mathrm{t}, J=8.5 \mathrm{~Hz}, 1 \mathrm{H}), 7.43\left(\mathrm{dd}, J_{1}=8.5 \mathrm{~Hz}, J_{2}=2.0 \mathrm{~Hz}\right.$, $1 \mathrm{H}), 7.47(\mathrm{t}, J=7.5 \mathrm{~Hz}, 1 \mathrm{H}), 7.50-7.56(\mathrm{~m}, 1 \mathrm{H}), 9.03(\mathrm{~d}$, $J=1.5 \mathrm{~Hz}, 1 \mathrm{H}), 9.13(\mathrm{~d}, J=8.0 \mathrm{~Hz}, 1 \mathrm{H}), 11.11(\mathrm{~s}, 1 \mathrm{H}$, $\mathrm{NH}) .{ }^{13} \mathrm{C}$ NMR $\left(125 \mathrm{MHz}\right.$, DMSO- $\left.d_{6}\right): 20.0,20.3,20.4$, $20.5\left(\mathrm{CH}_{3}\right), 61.9\left(\mathrm{CH}_{2}\right), 67.3,67.8,72.5,73.2,78.3(\mathrm{CH})$, $111.1,112.0,122.5,128.6,129.1,132.4,133.2(\mathrm{CH}), 120.7$, $122.7,125.1,132.2,133.4,141.3,143.2$ (C), 167.0, 168.3, $168.8,169.4,169.5,170.0(\mathrm{C}=\mathrm{O})$.

4.1.10.4. 1-(2,3,4,6-Tetra-O-acetyl- $\beta$-D-glucopyranosyl)-5'-trifluoromethoxyisoindigo 20. Yield: $32 \%$. Red solid $\left(\mathrm{mp}=270^{\circ} \mathrm{C}\right)$. IR $(\mathrm{KBr}): \nu_{\mathrm{C}-\mathrm{O}} 1690-1795 \mathrm{~cm}^{-1} ; \nu_{\mathrm{NH}}$ $3220-3605 \mathrm{~cm}^{-1}$. HRMS (ES) calcd for $\mathrm{C}_{31} \mathrm{H}_{27} \mathrm{~F}_{3} \mathrm{~N}_{2} \mathrm{NaO}_{12}$ $(\mathrm{M}+\mathrm{Na})^{+}$699.1414, found 699.1416. ${ }^{1} \mathrm{H} \mathrm{NMR}(400 \mathrm{MHz}$, DMSO- $\left.d_{6}\right): 1.77\left(\mathrm{~s}, 3 \mathrm{H}, \mathrm{CH}_{3}\right), 1.96\left(\mathrm{~s}, 3 \mathrm{H}, \mathrm{CH}_{3}\right), 2.03(\mathrm{~s}$, $\left.3 \mathrm{H}, \mathrm{CH}_{3}\right), 2.05\left(\mathrm{~s}, 3 \mathrm{H}, \mathrm{CH}_{3}\right), 4.10-4.19(\mathrm{~m}, 2 \mathrm{H}), 4.33-4.40$ $(\mathrm{m}, 1 \mathrm{H}), 5.28-5.39(\mathrm{~m}, 1 \mathrm{H}), 5.53-5.71(\mathrm{~m}, 2 \mathrm{H}), 6.11-6.21$ $(\mathrm{m}, 1 \mathrm{H}), 6.94(\mathrm{~d}, J=8.5 \mathrm{~Hz}, 1 \mathrm{H}), 7.12(\mathrm{t}, J=8.0 \mathrm{~Hz}, 1 \mathrm{H})$, $7.41\left(\mathrm{dd}, J_{1}=8.5 \mathrm{~Hz}, J_{2}=1.5 \mathrm{~Hz}, 1 \mathrm{H}\right), 7.48(\mathrm{t}, J=7.5 \mathrm{~Hz}$, $1 \mathrm{H}), 7.51-7.57(\mathrm{~m}, 1 \mathrm{H}), 9.01(\mathrm{~s}, 1 \mathrm{H}), 9.15(\mathrm{~d}, J=8.0 \mathrm{~Hz}$, $1 \mathrm{H}), 11.16(\mathrm{~s}, 1 \mathrm{H}, \mathrm{NH}) .{ }^{13} \mathrm{C}$ NMR $\left(100 \mathrm{MHz}, \mathrm{DMSO}-d_{6}\right)$ : 19.9, 20.2, 20.4, $20.5\left(\mathrm{CH}_{3}\right), 61.9\left(\mathrm{CH}_{2}\right), 67.3,67.8,72.5$, $73.1,78.3(\mathrm{CH}), 110.5,112.2,122.3,122.5,126.1,129.1$, $133.3(\mathrm{CH}), 120.3\left(\mathrm{q}, J_{\mathrm{C}, \mathrm{F}}=255 \mathrm{~Hz}, \mathrm{OCF}_{3}\right), 120.7,122.1$, $132.4,133.5,141.3,142.3,143.4$ (C), 167.0, 168.5, 168.8, $169.4,169.5,170.0(\mathrm{C}=\mathrm{O})$.

4.1.10.5. 5'-Bromo-1-(2,3,4,6-tetra-O-acetyl- $\beta$-D-glucopyranosyl)isoindigo 21 . Yield: $41 \%$. Red solid $\left(\mathrm{mp}>290^{\circ} \mathrm{C}\right)$. IR $(\mathrm{KBr}): \nu_{\mathrm{C}=\mathrm{C}} 1610 \mathrm{~cm}^{-1} ; \quad \nu_{\mathrm{C}=\mathrm{O}} \quad 1700-1790 \mathrm{~cm}^{-1} ; \nu_{\mathrm{NH}}$ $3310-3600 \mathrm{~cm}^{-1}$. HRMS (ES) calcd for $\mathrm{C}_{30} \mathrm{H}_{27}{ }^{79} \mathrm{BrN}_{2} \mathrm{NaO}_{11}$ $(\mathrm{M}+\mathrm{Na})^{+}$693.0696, found 693.0717. ${ }^{1} \mathrm{H} \mathrm{NMR}(400 \mathrm{MHz}$, DMSO- $\left.d_{6}\right): 1.78\left(\mathrm{~s}, 3 \mathrm{H}, \mathrm{CH}_{3}\right), 1.96\left(\mathrm{~s}, 3 \mathrm{H}, \mathrm{CH}_{3}\right), 2.03(\mathrm{~s}$, 
$\left.3 \mathrm{H}, \mathrm{CH}_{3}\right), 2.05\left(\mathrm{~s}, 3 \mathrm{H}, \mathrm{CH}_{3}\right), 4.10-4.19(\mathrm{~m}, 2 \mathrm{H}), 4.32-4.39$ $(\mathrm{m}, 1 \mathrm{H}), 5.28-5.39(\mathrm{~m}, 1 \mathrm{H}), 5.58(\mathrm{t}, J=8.5 \mathrm{~Hz}, 1 \mathrm{H}), 5.54-$ $5.70(\mathrm{~m}, 1 \mathrm{H}), 6.11-6.20(\mathrm{~m}, 1 \mathrm{H}), 6.82(\mathrm{~d}, J=8.5 \mathrm{~Hz}, 1 \mathrm{H})$, $7.11(\mathrm{t}, J=7.5 \mathrm{~Hz}, 1 \mathrm{H}), 7.47(\mathrm{t}, J=7.5 \mathrm{~Hz}, 1 \mathrm{H}), 7.49-7.58$ $(\mathrm{m}, 2 \mathrm{H}), 9.13(\mathrm{~d}, J=8.0 \mathrm{~Hz}, 1 \mathrm{H}), 9.17(\mathrm{~s}, 1 \mathrm{H}), 11.11(\mathrm{~s}$, $1 \mathrm{H}, \mathrm{NH}) .{ }^{13} \mathrm{C}$ NMR (100 MHz, DMSO- $d_{6}$ ): $19.9,20.3,20.4$, $20.5\left(\mathrm{CH}_{3}\right), 61.9\left(\mathrm{CH}_{2}\right), 67.3,67.8,72.5,73.1,78.3(\mathrm{CH})$, $111.6,112.1,122.5,129.1,131.3,133.2,135.1(\mathrm{CH}), 112.8$, $120.7,123.2,132.2,133.3,141.3,143.5$ (C), 167.0, 168.2, $168.8,169.4,169.5,170.0(\mathrm{C}=\mathrm{O})$.

4.1.10.6. 5'-Chlorosulfonyl-1-(2,3,4,6-tetra-O-acetyl- $\beta$-D-glucopyranosyl)isoindigo 22. Yield: 9\%. Red solid $\left(\mathrm{mp}=235^{\circ} \mathrm{C}\right)$. IR $(\mathrm{KBr}): \nu_{\mathrm{C}=\mathrm{C}} 1611 \mathrm{~cm}^{-1} ; \nu_{\mathrm{C}=\mathrm{O}} 1690-$ $1795 \mathrm{~cm}^{-1} ; \nu_{\mathrm{NH}} 3200-3600 \mathrm{~cm}^{-1}$. HRMS (ES) calcd for $\mathrm{C}_{30} \mathrm{H}_{27}{ }^{35} \mathrm{ClN}_{2} \mathrm{NaO}_{13} \mathrm{~S}(\mathrm{M}+\mathrm{Na})^{+} 713.0820$, found 713.0841 . ${ }^{1} \mathrm{H}$ NMR (400 MHz, DMSO- $\left.d_{6}\right): 1.78\left(\mathrm{~s}, 3 \mathrm{H}, \mathrm{CH}_{3}\right), 1.95$ (s, $\left.3 \mathrm{H}, \mathrm{CH}_{3}\right), 2.03\left(\mathrm{~s}, 3 \mathrm{H}, \mathrm{CH}_{3}\right), 2.04\left(\mathrm{~s}, 3 \mathrm{H}, \mathrm{CH}_{3}\right), 4.12-4.18$ $(\mathrm{m}, 2 \mathrm{H}), 4.33-4.40(\mathrm{~m}, 1 \mathrm{H}), 5.27-5.37(\mathrm{~m}, 1 \mathrm{H}), 5.51-5.68$ $(\mathrm{m}, 2 \mathrm{H}), 6.11-6.22(\mathrm{~m}, 1 \mathrm{H}), 6.79(\mathrm{~d}, J=8.0 \mathrm{~Hz}, 1 \mathrm{H}), 7.09$ $(\mathrm{t}, J=7,0 \mathrm{~Hz}, 1 \mathrm{H}), 7.44(\mathrm{t}, J=7.0 \mathrm{~Hz}, 1 \mathrm{H}), 7.48-7.54(\mathrm{~m}$, $1 \mathrm{H}), 7.63$ (d, $J=7.5 \mathrm{~Hz}, 1 \mathrm{H}), 9.10(\mathrm{~d}, J=7.5 \mathrm{~Hz}, 1 \mathrm{H}), 9.28$ (s, $1 \mathrm{H}), 11.04(\mathrm{~s}, 1 \mathrm{H}, \mathrm{NH}) .{ }^{13} \mathrm{C}$ NMR $(100 \mathrm{MHz}$, DMSO$\left.d_{6}\right): 20.0,20.3,20.4,20.5\left(\mathrm{CH}_{3}\right), 61.8\left(\mathrm{CH}_{2}\right), 67.3,67.8$, $72.6,73.1,78.3(\mathrm{CH}), 108.6,112.0,122.3,127.0,128.7$, $130.8,132.6(\mathrm{CH}), 120.6,120.9,134.8,141.1,142.1(2 \mathrm{C})$, 144.5 (C), 166.7, 168.8, 168.9, $169.4(2 \mathrm{C}), 170.1(\mathrm{C}=\mathrm{O})$.

4.1.10.7. $\quad 5^{\prime}-\mathrm{N}$-Methylaminosulfonyl-1-(2,3,4,6-tetra-O-acetyl$\beta$-D-glucopyranosyl)isoindigo 23. Yield: $10 \%$. Red solid $\left(\mathrm{mp}=231^{\circ} \mathrm{C}\right)$. IR $(\mathrm{KBr}): \nu_{\mathrm{C}-\mathrm{C}} 1617 \mathrm{~cm}^{-1} ; \nu_{\mathrm{C}=\mathrm{O}} 1700-$ $1780 \mathrm{~cm}^{-1} ; \nu_{\mathrm{NH}} 3230-3610 \mathrm{~cm}^{-1}$. HRMS (ES) calcd for $\mathrm{C}_{31} \mathrm{H}_{31} \mathrm{~N}_{3} \mathrm{NaO}_{13} \mathrm{~S}(\mathrm{M}+\mathrm{Na})^{+} 708.1475$, found 708.1496. ${ }^{1} \mathrm{H}$ NMR $\left(400 \mathrm{MHz}, \mathrm{DMSO}-d_{6}\right): 1.78\left(\mathrm{~s}, 3 \mathrm{H}, \mathrm{CH}_{3}\right), 1.96(\mathrm{~s}, 3 \mathrm{H}$, $\left.\mathrm{CH}_{3}\right), 2.03\left(\mathrm{~s}, 3 \mathrm{H}, \mathrm{CH}_{3}\right), 2.05\left(\mathrm{~s}, 3 \mathrm{H}, \mathrm{CH}_{3}\right), 2.44$ (d, $J=4.5 \mathrm{~Hz}, 3 \mathrm{H}), 4.10-4.19(\mathrm{~m}, 2 \mathrm{H}), 4.35-4.42(\mathrm{~m}, 1 \mathrm{H})$, $5.29-5.39(\mathrm{~m}, 1 \mathrm{H}), 5.53-5.68(\mathrm{~m}, 2 \mathrm{H}), 6.13-6.22(\mathrm{~m}, 1 \mathrm{H})$, $7.05(\mathrm{~d}, J=8.0 \mathrm{~Hz}, 1 \mathrm{H}), 7.12(\mathrm{t}, J=7.5 \mathrm{~Hz}, 1 \mathrm{H}), 7.29-7.35$ $(\mathrm{m}, 1 \mathrm{H}, \mathrm{NH}), 7.48(\mathrm{t}, J=7.5 \mathrm{~Hz}, 1 \mathrm{H}), 7.52-7.57(\mathrm{~m}, 1 \mathrm{H})$, $7.78(\mathrm{~d}, J=8.0 \mathrm{~Hz}, 1 \mathrm{H}), 9.13(\mathrm{~d}, J=8.0 \mathrm{~Hz}, 1 \mathrm{H}), 9.46(\mathrm{~s}$, $1 \mathrm{H}), 11.40(\mathrm{~s}, 1 \mathrm{H}, \mathrm{NH}) .{ }^{13} \mathrm{C}$ NMR $\left(100 \mathrm{MHz}\right.$, DMSO- $\left.d_{6}\right)$ : 19.9, 20.3, 20.4, 20.5, $28.7\left(\mathrm{CH}_{3}\right), 61.9\left(\mathrm{CH}_{2}\right), 67.4,67.8$, $72.5,73.1,78.3(\mathrm{CH}), 110.1,112.3,122.5,128.1,129.1$, 131.6, $133.4(\mathrm{CH}), 120.7,121.2,132.0,132.5,133.1,141.4$, $147.3(\mathrm{C}), 166.9,168.7,168.9,169.4,169.5,170.1(\mathrm{C}=\mathrm{O})$.

4.1.10.8. 5 -(1-Oxobutyl)-1-(2,3,4,6-tetra-O-acetyl- $\beta$-D-glucopyranosyl)isoindigo 24 . Yield: $12 \%$. Red solid $\left(\mathrm{mp}=210^{\circ} \mathrm{C}\right)$. IR (KBr): $\nu_{\mathrm{C}-\mathrm{C}} 1612 \mathrm{~cm}^{-1} ; \nu_{\mathrm{C}=\mathrm{O}} 1675-1785 \mathrm{~cm}^{-1} ; \nu_{\mathrm{NH}}$ $3175-3520 \mathrm{~cm}^{-1}$. HRMS (ES) calcd for $\mathrm{C}_{34} \mathrm{H}_{34} \mathrm{~N}_{2} \mathrm{NaO}_{12}$ $(\mathrm{M}+\mathrm{Na})^{+} 685.2009$, found $685.1990 .{ }^{1} \mathrm{H}$ NMR $(400 \mathrm{MHz}$, DMSO- $d_{6}$ ): 0.95 (t, $J=7.5 \mathrm{~Hz}, 3 \mathrm{H}, \mathrm{CH}_{3}$ ), 1.67 (sext, $\left.J=7.5 \mathrm{~Hz}, 2 \mathrm{H}, \mathrm{CH}_{2}\right), 1.78\left(\mathrm{~s}, 3 \mathrm{H}, \mathrm{CH}_{3}\right), 1.96\left(\mathrm{~s}, 3 \mathrm{H}, \mathrm{CH}_{3}\right)$ $2.03\left(\mathrm{~s}, 3 \mathrm{H}, \mathrm{CH}_{3}\right), 2.05\left(\mathrm{~s}, 3 \mathrm{H}, \mathrm{CH}_{3}\right), 2.95(\mathrm{t}, J=7.0 \mathrm{~Hz}$, $\left.2 \mathrm{H}, \mathrm{CH}_{2}\right), 4.12-4.19(\mathrm{~m}, 2 \mathrm{H}), 4.36-4.43(\mathrm{~m}, 1 \mathrm{H}), 5.28-$ $5.41(\mathrm{~m}, 1 \mathrm{H}), 5.55-5.70(\mathrm{~m}, 2 \mathrm{H}), 6.13-6.24(\mathrm{~m}, 1 \mathrm{H}), 6.95$ (d, $J=8.0 \mathrm{~Hz}, 1 \mathrm{H}), 7.12$ (t, $J=7.0 \mathrm{~Hz}, 1 \mathrm{H}), 7.47$ (t,
$J=7.5 \mathrm{~Hz}, 1 \mathrm{H}), 7.49-7.57(\mathrm{~m}, 1 \mathrm{H}), 8.02\left(\mathrm{dd}, J_{1}=8.5 \mathrm{~Hz}\right.$, $\left.J_{2}=1.5 \mathrm{~Hz}, 1 \mathrm{H}\right), 9.11(\mathrm{~d}, J=8.0 \mathrm{~Hz}, 1 \mathrm{H}), 9.64(\mathrm{~s}, 1 \mathrm{H})$, $11.36(\mathrm{~s}, 1 \mathrm{H}, \mathrm{NH}) .{ }^{13} \mathrm{C}$ NMR $\left(100 \mathrm{MHz}, \mathrm{DMSO}-d_{6}\right): 13.7$, 19.9, 20.3, 20.4, $20.5\left(\mathrm{CH}_{3}\right), 17.5,39.4,61.9\left(\mathrm{CH}_{2}\right), 67.4$, $67.8,72.5,73.0,78.3(\mathrm{CH}), 109.6,112.1,122.4,129.0$, $129.6,133.1,133.4(\mathrm{CH}), 120.8,121.3,130.5,131.9,133.7$, $141.2,148.0$ (C), 166.9, 168.8, 168.9, 169.4, 169.5, 170.0, $198.4(\mathrm{C}=\mathrm{O})$.

4.1.10.9. 6-Nitro-5'-(1-oxobutyl)-1-(2,3,4,6-tetra-O-acetyl- $\beta$ D-glucopyranosyl)isoindigo 25. Yield: $63 \%$. Red solid $\left(\mathrm{mp}>250^{\circ} \mathrm{C}\right)$. IR $(\mathrm{KBr}): \nu_{\mathrm{C}=\mathrm{C}} 1618 \mathrm{~cm}^{-1} ; \nu_{\mathrm{C}=\mathrm{O}} 1690-$ $1780 \mathrm{~cm}^{-1} ; \nu_{\mathrm{NH}} 3125-3670 \mathrm{~cm}^{-1}$. HRMS (ES) calcd for $\mathrm{C}_{34} \mathrm{H}_{33} \mathrm{~N}_{3} \mathrm{NaO}_{14}(\mathrm{M}+\mathrm{Na})^{+} 730.1860$, found $730.1886 .{ }^{1} \mathrm{H}$ NMR $\left(400 \mathrm{MHz}\right.$, DMSO- $\left.d_{6}\right): 0.95\left(\mathrm{t}, J=7.5 \mathrm{~Hz}, 3 \mathrm{H}, \mathrm{CH}_{3}\right)$, 1.68 (sext, $\left.J=7.5 \mathrm{~Hz}, 2 \mathrm{H}, \mathrm{CH}_{2}\right), 1.79\left(\mathrm{~s}, 3 \mathrm{H}, \mathrm{CH}_{3}\right), 1.98$ (s, $\left.3 \mathrm{H}, \mathrm{CH}_{3}\right), 2.06\left(\mathrm{~s}, 3 \mathrm{H}, \mathrm{CH}_{3}\right), 2.07\left(\mathrm{~s}, 3 \mathrm{H}, \mathrm{CH}_{3}\right), 2.95(\mathrm{t}$, $\left.J=7.0 \mathrm{~Hz}, 2 \mathrm{H}, \mathrm{CH}_{2}\right), 4.14\left(\mathrm{dd}, J_{1}=12.5 \mathrm{~Hz}, J_{2}=2.0 \mathrm{~Hz}\right.$, $1 \mathrm{H}), 4.24\left(\mathrm{dd}, J_{1}=12.5 \mathrm{~Hz}, J_{2}=3.5 \mathrm{~Hz}, 1 \mathrm{H}\right), 4.42-4.48$ $(\mathrm{m}, 1 \mathrm{H}), 5.26-5.37(\mathrm{~m}, 1 \mathrm{H}), 5.49-5.68(\mathrm{~m}, 1 \mathrm{H}), 5.68(\mathrm{t}$, $J=9.0 \mathrm{~Hz}, \quad 1 \mathrm{H}), \quad 6.29 \quad(\mathrm{~d}, \quad J=9.0 \mathrm{~Hz}, 1 \mathrm{H}), \quad 6.97 \quad(\mathrm{~d}$, $J=8.0 \mathrm{~Hz}, 1 \mathrm{H}), 8.00\left(\mathrm{dd}, J_{1}=9.0 \mathrm{~Hz}, J_{2}=2.0 \mathrm{~Hz}, 1 \mathrm{H}\right)$, $8.07(\mathrm{~d}, J=8.0 \mathrm{~Hz}, 1 \mathrm{H}), 8.15(\mathrm{~d}, J=1.5 \mathrm{~Hz}, 1 \mathrm{H}), 9.32(\mathrm{~d}$, $J=9.0 \mathrm{~Hz}, 1 \mathrm{H}), 9.62(\mathrm{~s}, 1 \mathrm{H}) 11.47(\mathrm{~s}, 1 \mathrm{H}, \mathrm{NH}) .{ }^{13} \mathrm{C} \mathrm{NMR}$ $\left(100 \mathrm{MHz}\right.$, DMSO-d $\left.d_{6}\right): 13.7,19.9,20.3(2 \mathrm{C}), 20.4\left(\mathrm{CH}_{3}\right)$, $17.4,39.5,61.1\left(\mathrm{CH}_{2}\right), 67.2,67.7,72.0,73.1,78.8(\mathrm{CH})$, $105.9,110.0,117.6,129.5,130.4,134.8(\mathrm{CH}), 121.0,126.4$, $129.2,130.7,137.8,141.5,149.0,149.1$ (C), 166.5, 168.5, $169.1,169.3,169.5,170.0,198.2(\mathrm{C}=\mathrm{O})$.

4.1.10.10. 7 -Aza-1-(2,3,4,6-tetra-O-acetyl- $\beta$-D-glucopyranosyl)isoindigo 26. Yield: $10 \%$. Red solid $\left(\mathrm{mp}=196^{\circ} \mathrm{C}\right)$. IR $(\mathrm{KBr}): \quad \nu_{\mathrm{C}-\mathrm{C}} \quad 1603 \mathrm{~cm}^{-1} ; \quad \nu_{\mathrm{C}=\mathrm{O}} \quad 1690-1790 \mathrm{~cm}^{-1} ; \quad \nu_{\mathrm{NH}}$ $3240-3625 \mathrm{~cm}^{-1}$. HRMS (ES): calcd for $\mathrm{C}_{29} \mathrm{H}_{28} \mathrm{~N}_{3} \mathrm{O}_{11}$ $(\mathrm{M}+\mathrm{H})^{+}$594.1724, found 594.1712. ${ }^{1} \mathrm{H}$ NMR $(500 \mathrm{MHz}$, DMSO- $\left.d_{6}\right): 1.77\left(\mathrm{~s}, 3 \mathrm{H}, \mathrm{CH}_{3}\right), 1.96\left(\mathrm{~s}, 3 \mathrm{H}, \mathrm{CH}_{3}\right), 2.02(\mathrm{~s}$, $\left.3 \mathrm{H}, \mathrm{CH}_{3}\right), 2.05\left(\mathrm{~s}, 3 \mathrm{H}, \mathrm{CH}_{3}\right), 4.10-4.18(\mathrm{~m}, 2 \mathrm{H}), 4.33-4.40$ $(\mathrm{m}, 1 \mathrm{H}), 5.27-5.41(\mathrm{~m}, 1 \mathrm{H}), 5.52-5.68(\mathrm{~m}, 2 \mathrm{H}), 6.04-6.16$ $(\mathrm{m}, 1 \mathrm{H}), 7.06\left(\mathrm{dd}, J_{1}=7.5 \mathrm{~Hz}, J_{2}=5.5 \mathrm{~Hz}, 1 \mathrm{H}\right), 7.13(\mathrm{t}$, $J=7.5 \mathrm{~Hz}, 1 \mathrm{H}), 7.48(\mathrm{t}, J=7.5 \mathrm{~Hz}, 1 \mathrm{H}), 7.51-7.59(\mathrm{~m}$, $1 \mathrm{H}), 8.20(\mathrm{~d}, J=5.0 \mathrm{~Hz}, 1 \mathrm{H}), 9.14(\mathrm{~d}, J=8.0 \mathrm{~Hz}, 1 \mathrm{H}), 9.17$ $(\mathrm{d}, \quad J=8.0 \mathrm{~Hz}, 1 \mathrm{H}), \quad 11.59(\mathrm{~s}, 1 \mathrm{H}, \quad \mathrm{NH}),{ }^{13} \mathrm{C} \quad \mathrm{NMR}$ (125 MHz, DMSO- $\left.d_{6}\right): 20.0,20.3,20.4,20.5\left(\mathrm{CH}_{3}\right), 61.9$ $\left(\mathrm{CH}_{2}\right), 67.3,67.8,72.5,73.1,78.3(\mathrm{CH}), 111.6,117.7$, $122.6,129.1,133.2,136.4,150.5(\mathrm{CH}), 116.1,120.6,132.1$, $132.5,141.3,157.9$ (C), 167.0, 168.2, 168.8, 169.4, 169.5, $170.0(\mathrm{C}=\mathrm{O})$.

4.1.10.11. 7'-Aza-5'-bromo-1-(2,3,4,6-tetra-O-acetyl- $\beta$-D-glucopyranosyl)isoindigo 27. Yield: 55\%. Red solid $\left(\mathrm{mp}=228-230^{\circ} \mathrm{C}\right) . \quad \mathrm{IR} \quad(\mathrm{KBr}): \nu_{\mathrm{C}=\mathrm{C}} 1617 \mathrm{~cm}^{-1} ; \nu_{\mathrm{C}=\mathrm{O}}$ $1715-1800 \mathrm{~cm}^{-1} ; \nu_{\mathrm{NH}} 3300-3600 \mathrm{~cm}^{-1}$. HRMS (ES): calcd for $\mathrm{C}_{29} \mathrm{H}_{27}{ }^{79} \mathrm{BrN}_{3} \mathrm{O}_{11}(\mathrm{M}+\mathrm{H})^{+} 672.0829$, found 672.0833 . ${ }^{1} \mathrm{H}$ NMR $\left(500 \mathrm{MHz}, \mathrm{DMSO}-d_{6}\right): 1.78\left(\mathrm{~s}, 3 \mathrm{H}, \mathrm{CH}_{3}\right), 1.96(\mathrm{~s}$, $\left.3 \mathrm{H}, \mathrm{CH}_{3}\right), 2.03\left(\mathrm{~s}, 3 \mathrm{H}, \mathrm{CH}_{3}\right), 2.05\left(\mathrm{~s}, 3 \mathrm{H}, \mathrm{CH}_{3}\right), 4.10-4.18$ $(\mathrm{m}, 2 \mathrm{H}), 4.32-4.38(\mathrm{~m}, 1 \mathrm{H}), 5.29-5.40(\mathrm{~m}, 1 \mathrm{H}), 5.52-5.68$ $(\mathrm{m}, 1 \mathrm{H}), 5.58(\mathrm{t}, J=9.0 \mathrm{~Hz}, 1 \mathrm{H}), 6.10-6.20(\mathrm{~m}, 1 \mathrm{H}), 7.15$ 
$(\mathrm{t}, J=8.0 \mathrm{~Hz}, 1 \mathrm{H}), 7.50(\mathrm{t}, J=7.5 \mathrm{~Hz}, 1 \mathrm{H}), 7.53-7.60(\mathrm{~m}$, $1 \mathrm{H}), 8.34(\mathrm{~d}, J=2.0 \mathrm{~Hz}, 1 \mathrm{H}), 9.15(\mathrm{~d}, J=8.0 \mathrm{~Hz}, 1 \mathrm{H}), 9.40$ (br s, $1 \mathrm{H}), 11.80($ br s, $1 \mathrm{H}, \mathrm{NH}) .{ }^{13} \mathrm{C}$ NMR $(100 \mathrm{MHz}$, DMSO- $\left.d_{6}\right): 20.0,20.2,20.4,20.5\left(\mathrm{CH}_{3}\right), 61.9\left(\mathrm{CH}_{2}\right), 67.2$, $67.8,72.5,73.2,78.3(\mathrm{CH}), 111.8,122.7,129.4,133.8$, $138.2,150.1(\mathrm{CH}), 111.9,117.8,120.5,131.2,133.5,141.6$, 156.5 (C), 167.1, 167.9, 168.9, 169.3, 169.5, $170.0(\mathrm{C}=\mathrm{O})$.

\subsection{Antiproliferative activities}

\subsubsection{Cell cultures and proliferation assays}

Stock cell cultures were maintained as monolayers in $75 \mathrm{~cm}^{2}$ culture flasks in Glutamax RPMI medium with $10 \%$ fetal calf serum containing penicillin and streptomycin. Cells were grown at $37^{\circ} \mathrm{C}$ in a humidified incubator under an atmosphere containing $5 \% \mathrm{CO}_{2}$. Cells were plated at a density of $500-800$ cells in $200 \mu \mathrm{L}$ culture medium in each well of 96-well microplates and were allowed to adhere for $24 \mathrm{~h}$ before treatment with tested drugs in DMSO solution (final concentration of $10^{-5} \mathrm{M}$ ). Cell viability was assayed after $72 \mathrm{~h}$ continuous drug exposure with a tetrazolium compound [3-(4,5-dimethylthiazol-2-yl)-5-(3-carboxymethoxyphenyl)-2(4-sulfophenyl)- $2 \mathrm{H}$-tetrazolium salt, MTS, Promega Corp] by CellTiter 96 Aqueous One Solution Cell Proliferation Assay kit (Promega Corp) according to the manufacturer's instructions. Absorbance was measured at $490 \mathrm{~nm}$ with a microplate reader.

\section{Acknowledgements}

The authors are grateful to Prof. Michelle Prudhomme for helpful discussions and to Bertrand Légeret for mass spectra analysis.

\section{References}

[1] M. Sassatelli, E. Saab, F. Anizon, M. Prudhomme, P. Moreau, Tetrahedron Lett. 45 (2004) 4827-4830.

[2] M. Sassatelli, F. Bouchikhi, S. Messaoudi, F. Anizon, E. Debiton, C. Barthomeuf, M. Prudhomme, P. Moreau, Eur. J. Med. Chem. 41 (2006) $88-100$.

[3] P. Stjernlof, M.D. Ennis, L.O. Hansson, R.L. Hoffman, N.B. Ghazal, S. Sundell, M.W. Smith, K. Svensson, A. Carlsson, H. Wikstrom, J. Med. Chem. 38 (1995) 2202-2216.

[4] A. Marfat, M.P. Carta, Tetrahedron Lett. 28 (1987) 4027-4030.

[5] S. Okuda, M.M. Robison, J. Am. Chem. Soc. 81 (1959) 740-743.

[6] L. Sun, N. Tran, F. Tang, H. App, P. Hirth, G. McMahon, C. Tang, J. Med. Chem. 41 (1998) 2588-2603.

[7] D. Mazéas, G. Guillaumet, M.-C. Viaud, Heterocycles 50 (1999) 10651080 .

[8] M.S.C. Pedras, M. Jha, J. Org. Chem. 70 (2005) 1828-1834.

[9] M. Kakushima, P. Hamel, R. Frenette, J. Rokach, J. Org. Chem. 48 (1983) 3214-3219.

[10] L. Sun, N. Tran, C. Liang, F. Tang, A. Rice, R. Schreck, K. Waltz, L.K. Shawver, G. McMahon, C. Tang, J. Med. Chem. 42 (1999) $5120-5130$.

[11] H. Guan, A.D. Laird, R.A. Blake, C. Tang, C. Liang, Bioorg. Med. Chem. Lett. 14 (2004) 187-190. 